\title{
ABORDAGENS TEÓRICO-METODOLÓGICAS DA FORMAÇÃO DE PROFESSORES EM DOIS TEMPOS: OLHARES SOBRE O CIPA I (2004) E O CIPA V (2012)
}

\author{
- INÊS FERREIRA DE SOUZA BRAGANÇA \\ Universidade do Estado do Rio de Janeiro \\ MARIA HELENA MENNA BARRETO ABRAHÃO \\ Universidade Federal de Pelotas
}

RESUMO

O presente texto retoma pesquisa que consistiu no estudo da produção dos Congressos Internacionais de Pesquisa (Auto)biográfica (CIPA), tendo em vista o levantamento de indícios sobre os movimentos teórico-metodológicos do campo. Partilhamos, aqui, um recorte do trabalho que focalizou 11 capítulos do livro do I CIPA e $34 \mathrm{da}$ coleção de 9 livros relativos ao V CIPA, tendo como filtro a formação de professores, especificamente os textos voltados para uma abordagem geral/teórica sobre as dinâmicas de formação docente em diálogo com a perspectiva (auto)biográfica e os trabalhos voltados para práticas de formação, incluindo formação inicial, continuada e desenvolvida no contexto escolar. Iniciamos com o olhar dirigido para o I e o V CIPA, tecemos um diálogo entre os referenciais teórico-metodológicos que fundamentam as pesquisas desenvolvidas e finalizamos com reflexões que apontam para a continuidade do estudo.

Palavras-chave: Abordagem (auto)biográfica. Formação de professores. Congresso Internacional de Pesquisa (Auto)Biográfica.

\section{ABSTRACT THEORETICAL-METHODOLOGICAL APPROACHES OF TEACHER TRAINING IN TWO TIMES: VIEWS ON THE CIPA I (2004) AND CIPA V (2012)}

The present text takes up research that consisted in the study of the production of International Congresses of (Auto)Biographical Research (CIPAs), with a view to lifting of indications on the movements of the methodological-theoretical field. We share, in this paper, a clipping of the work that has focused on 11 chapters of the book of I CIPA and 34 chapters of the collection of 9 books relating to V CIPA, having teachers' training as filter, specifically texts facing a gener- 
al/theoretical approach about the dynamics of teaching education in dialog with the prospect (auto)biographical and work directed to practices of training, including initial and continued training developed in the school context. We started with a gaze turned to the I and to the V CIPA, made a dialog among the theoretical-methodological approaches adopted that underpin the researches developed and finalized with reflections that point to the continuity of this study.

Keywords: (Auto)biographical approach. Teacher training. International Congress of (Auto)Biographical Research.

\section{RESUMEN ABORDAJESTEÓRICOS-METODOLÓGICOS DE LA FORMACIÓN DOCENTE EN DOS MOMENTOS: MIRADAS SOBRE EL CIPA I (2004) Y CIPA V (2012)}

El presente texto continua la investigación que consistió en el estudio de la producción de los Congresos Internacionales de Investigación (Auto)biográfica (CIPA) teniendo, en vista la observación de vestigios sobre los movimientos teórico-metodológicos del campo. Compartimos aquí un fragmento del trabajo que focalizó 11 capítulos del libro del I CIPA y 34 de la colección de 9 libros referentes al V CIPA, teniendo como énfasis la formación de docentes, textos específicamente destinados para un enfoque general/teórica sobre las dinámicas de formación del profesorado en diálogo con la perspectiva de (auto) biográfica y trabajos dirigidos a las prácticas de formación, incluyendo la formación inicial, continuada y desarrollada en el contexto escolar. Comenzamos con la Mirada dirigida para el I y V de la CIPA, entrelazamos un diálogo entre los referentes teóricos-metodológicos que fundamentan las investigaciones desarrolladas y finalizamos con reflexiones relacionadas con la continuidad del estudio.

Palabras clave: Enfoque (auto)biográfico. Formación del docente. Congreso Internacional de Investigación (Auto)Biográfica.

\section{Introdução}

O presente texto retoma uma das dimensões de pesquisa que consistiu no estudo da produção dos Congressos Internacionais de Pesquisa (Auto)biográfica (CIPA), tendo em vista o levantamento de indícios sobre os movimentos teórico-metodológicos do campo. ${ }^{1}$

1 Apresentamos aqui um recorte da pesquisa realizada entre os anos de 2013 e 2014, no pós-doutoramento junto ao Programa de Pós-Graduação da Pontifícia Universidade Católica do Rio Grande do Sul (PUCRS),
No presente texto, partilhamos o estudo de 11 capítulos do livro do I CIPA e 34 da coleção de 9 livros relativos ao V CIPA, tendo como filtro a formação de professores, especificamente os textos voltados para: 1) uma abordagem geral/ teórica sobre as dinâmicas de formação docente, em diálogo com a perspectiva (auto)biográfica; e 2) trabalhos voltados para práticas de formação, incluindo formação inicial, continuada

em Porto Alegre, tendo como orientadora a Professora Maria Helena Menna Barreto Abrahão. 
e desenvolvida no contexto escolar. Iniciamos com o olhar dirigido para o I e o V CIPA; tecemos um diálogo entre os referenciais teóricometodológicos que fundamentam as pesquisas desenvolvidas e finalizamos com reflexões que apontam para a continuidade do estudo. ${ }^{2}$

\section{Olhar dirigido ao I e ao V CIPA}

O I Congresso Internacional de Pesquisa (Auto) Biográfica trouxe a força do sentido de aventura, presente no título proposto. Abrahão (2004) organizou a obra coletiva sobre a abordagem (auto)biográfica e, a partir do livro, foi tecida a proposta de realização do Congresso, tendo em vista reunir pesquisadores/autores para adensar as reflexões, favorecendo também o encontro e a partilha. Assim, Aventura (Auto) Biográfica: teoria e empiria é o título do livro e tema do I CIPA.

Iniciamos, então, um sobrevoo sobre o livro, trazendo elementos para essa reflexão, pontos comuns e tendências da abordagem (auto)biográfica, na discussão travada pelos pesquisadores, em Porto Alegre, no ano de 2004.

Só o folhear da obra traz indícios de sua densidade: 23 capítulos, com a participação de autores brasileiros e estrangeiros, e um total de 599 páginas (ABRAHÃO, 2013). Os temas que aglutinaram os capítulos constituíram os eixos temáticos para a apresentação de trabalhos no congresso, a saber: Dimensões metodológicas e epistemológicas da pesquisa (auto)biográfica; Memória, dimensões socio-históricas e

2 Como desdobramento da referida pesquisa, foi produzido o texto $A$ formação de professores em trabalhos apresentados no Congresso Internacional de Pesquisa (Auto)biográfica que sistematiza o estudo de quarenta trabalhos publicados nos anais (CD) do I, III, IV e V CIPA, especificamente inscritos no campo da formação de professores. A seleção dos textos estudados focalizou os eixos temáticos denominados: Histórias de vida e de trabalho de professores (I CIPA); Histórias de vida, narrativas, conhecimento de si, representações da docência (I CIPA); (Auto)biografia e práticas de formação: lugares de aprendizagem e (re)invenção de si (III CIPA) e Práticas de formação e pesquisas (auto) biográficas (IV e V CIPA). trajetórias (auto)biográficas; Gênero, geração, infância e família: perspectivas (auto)biográficas; Corpos, saúde e cuidado de si: desafios (auto)biográficos; Práticas de formação e pesquisas (auto)biográficas e Linguagens, narrativas (auto)biográficas e interculturalidades.

O prefácio, escrito por Larrosa (2004), abriu as cortinas do cenário no qual vêm se delineando conceitos caros à abordagem (auto) biográfica: narrativa, memória, experiência, processos identitários. Com o autor, mergulhamos em um "giro paradigmático" no qual, por um lado, o ser é impensável fora da interpretação e das relações discursivas e textuais e, por outro, um texto é impensável fora das relações com outros textos. Virada epistêmica pela qual o ser humano é um ser que se constitui no discurso sobre si próprio, que interpreta e se auto -interpreta na produção narrativa das tramas e intrigas que se articulam no ato de narrar, na produção de uma história que tenha sentido. No referido prefácio, Larrosa (2004) perspectiva o campo (auto)biográfico como muito criativo e de grande potência interdisciplinar, sem desconsiderar a tensão entre um paradigma teórico normatizado e movimentos que procuram não se enquadrar à normas (2004).

Do conjunto de capítulos do livro do I do CIPA, selecionamos seis com uma abordagem geral/teórica sobre as dinâmicas de formação docente, em diálogo com a perspectiva (auto) biográfica, e cinco trabalhos voltados para as práticas de formação, incluindo formação inicial, continuada e desenvolvida no contexto escolar.

Com base nesses capítulos, as duas primeiras mesas tematizaram aspectos teóricometodológicos. Dos textos lidos, três apresentam estudo teórico e dois fazem uma articulação entre a discussão teórica e o trabalho de campo, por meio de entrevistas narrativas. Os textos apontam para a preocupação dos autores no sentido de fundamentar teórica e epistemologicamente os caminhos trilhados 
na pesquisa (auto)biográfica, recorrendo, para essa tarefa, à contribuição de diferentes campos disciplinares. Os capítulos de Constantino (2004) e Oliveira (2004) recorrem à História Oral, para discutir a potencialidade das narrativas na pesquisa em educação. Já os textos de Fischer (2004), Mosquera e Stobäus (2004) e Moura (2004) trazem da Filosofia, da Psicologia e da Epistemologia conceitos-chave na tessitura do campo (auto)biográfico de pesquisa.

Tais referências teórico-metodológicas dialogam com a perspectiva de formação docente apresentada em cinco textos estudados, voltados, nomeadamente, para as práticas de formação. Os capítulos consistem em desdobramentos de investigações realizadas prioritariamente por grupos de pesquisa, o que aponta para o fato de que seus pesquisadores já contam com uma trajetória de estudo consolidada na área. A história oral, a história de vida e a narrativa de formação são as abordagens trabalhadas, especialmente por meio de entrevistas narrativas, observando-se um enfoque em narrativas orais, com abrangência temporal temática. O número de participantes nas pesquisas varia de 6 a 33 colaboradores. Quanto à metodologia de análise de dados, registramos a análise de conteúdo, de contexto (compreensão cênica) e a análise de discurso; dois textos não mencionaram a forma de análise. 0 referencial teórico tomado como fundamentação circunscreve autores do campo da filosofia, da história e das ciências da educação, em geral. No que se refere ao quadro de classificação organizado por Nóvoa (1992, p. 20), observamos uma concentração em objetivos essencialmente teóricos relacionados com a investigação, centrados na profissão e na prática docente.

Assumindo a metáfora do ciclo, em 2012, o Congresso retornou a Porto Alegre, em sua quinta edição, ciclo "que se fecha para poder voltar-se sobre si mesmo", assim como o movimento (auto)biográfico em sua tessitura de idas e voltas, retrospectivas e prospectivas (DELORY-MOMBERGER, 2012). Os dados quantitativos da produção já falam sobre o crescimento e a consolidação da produção do campo, tendo em vista que, nessa edição, foi produzida uma coleção de nove livros "com um total de 101 textos e 2.438 páginas" (ABRAHÃO, 2013 , p. 5). Desse universo, selecionamos 34 textos, sendo 19 relacionados ao referencial teórico-metodológico e 15 diretamente ligados às práticas de formação docente.

Apesar de constar no livro 1, Tomo II, dedicado à discussão metodológica, iniciamos esse sobrevoo sobre os capítulos estudados pelo belo texto de Josso (2012). Tomamos, aqui, a liberdade do adjetivo "belo", presente em nossa interpretação da obra da autora, pois a leitura de seus livros e textos nos aproxima da força formadora que caracteriza essa perspectiva de estudo. No texto Fecundação mútua de metodologia e de saberes em pesquisa-formação experiencial: observações fenomenológicas de figuras do acompanhamento e novas conceituações, a autora retoma um texto clássico, publicado em 1998, em que desenvolve os sentidos do caminhar com. O caminhar com implica a natureza relacional da pesquisa-formação (auto)biográfica e o processo de aprendizagem mútua entre pesquisa e pesquisador.

Dirigindo um olhar para o total de 15 textos selecionados, nos 9 livros da coleção, que apresentam um entrelaçamento entre discussão teórica e desenvolvimento de trabalho de campo, no âmbito da formação, percebemos que todos consistem em desdobramentos de pesquisa acadêmica, especialmente do trabalho de grupos de pesquisa. As abordagens adotadas sinalizam que seis pesquisas trabaIharam com histórias de vida, três com narrativas de vida e nas demais identificamos dois trabalhos em cada uma das abordagens, a saber, narrativas de formação, (auto)biografias e ateliês biográficos. 
Do ponto de vista metodológico, nesse universo de textos, destaca-se o predomínio significativo de narrativas escritas (nove trabalhos), seguindo-se a ênfase nas narrativas orais (três pesquisas) e com a utilização de dispositivos diversos. Percebemos um equilíbrio entre a abrangência temporal das pesquisas propostas, sendo oito em uma perspectiva global e sete na perspectiva temática das trajetórias de vida. O número de participantes variou de 2 a 24 , entretanto um número significativo de dez trabalhos não mencionou essa informação. Os contextos de pesquisa foram variados, incluindo o contexto escolar, as licenciaturas, especialmente a de Pedagogia, turmas de pósgraduação e de formação continuada de professores. Um quantitativo de dez capítulos não menciona a metodologia de análise de dados adotada, quatro fazem referência à análise hermenêutica e um à análise de conteúdo. 0 referencial teórico tomado como base dos trabalhos apresenta significativa presença das ciências da educação e, especificamente, do campo (auto)biográfico. Quatorze (14) pesquisas centram-se em objetivos emancipatórios relacionados com a investigação-formação, focalizando, preferencialmente, o atravessamento entre as três dimensões indicadas por Nóvoa (1992), a saber, a pessoa, a prática e a profissão.

Refletimos a seguir sobre os referenciais teórico-metodológicos que fundamentam os capítulos estudados, pela presença dos conceitos de formação, memória, narrativa e a discussão das perspectivas metodológicas de pesquisa.

\section{Itinerários da pesquisa (auto) biográfica no campo da formação de professores}

O conceito de formação humana encontra significativa presença nos textos estudados, tendo como referência um projeto ecobiocogniti- vo (SCHMUTZ-BRUN, 2012), traduzindo-se em um movimento de trans-formação existencial do sujeito, na mediação compartilhada com os outros e o mundo (PERES, 2012; PEREIRA, 2012; BARBOSA, 2012). Nas palavras de Araújo e Ribeiro (2012, p. 75): "a transformação de si como um devir em crescendo, enquanto processo de autoconhecimento que decorre de uma viagem de formação interior em que os múltiplos acontecimentos, encontros, conflitos e experiências felizes e infelizes".

Tal sentido conceitual é tomado também no que se refere à especificidade da formação docente, como um processo permanente de desenvolvimento pessoal-profissional, ao longo da vida (MONTEIRO et al., 2012; FRISON, 2012; ARANGO, 2012). É também compreendido como um movimento que implica intencionalidade reflexiva na produção de conhecimento "sobre si, sobre os outros e sobre o cotidiano [...]", pois "para a tomada de consciência, são necessárias reflexões referenciadas às aprendizagens e experiências construídas ao longo da vida [...]" (JOSSO, 2002 apud FONTOURA et al., 2012, p. 48), o que Alheit (2012) denomina de aprendizagem biográfica. Ou seja, professores que intencionalmente refletem sobre a trajetória ecobiocognitiva de suas práticas, não em um caminho solitário, mas em uma construção coletiva, que busca "interpretar a experiência por intermédio de uma mediação linguística compartilhada" (SCHMUTZ-BRUN, 2012, p. 30), um movimento que precisa ser lento para que fertilize a experiência, "olhar para si, diminuir a rapidez da própria vida, com vistas a assumir a reflexão" (BARREIRO, 2012, p. 193).

É importante registrar, entretanto, a advertência feita por Goodson (2004), em sua fala no I CIPA. $O$ autor desenvolveu um argumento explícito a favor do uso do método das histórias de vida no estudo dos professores, mas alerta para o fato de que nos anos de 1980 se tornaram intensas as práticas de controle político e 
administrativo dos professores. Nesse sentido, é significativo registrar que o trabalho com a abordagem (auto)biográfica, no campo da formação de professores, deve estimular sua potencialidade política, enquanto caminho para a narrativa dos coletivos docentes sobre seus fazeres e práticas que se colocam muitas vezes como microrresistências, táticas dos praticantes do cotidiano (CERTEAU, 2011).

O I CIPA coloca-se, na primeira metade dos anos 2000, no contexto do desenvolvimento multiforme da abordagem (auto)biográfica (PINEAU, 2006), em que os pesquisadores estavam se aproximando e buscando vivenciar a aventura (auto)biográfica de pesquisa, em suas diferentes possibilidades. A narrativa é então apresentada não como verdade, mas como "forma de representação do mundo subjetivo" (MOSQUERA; STOBÄUS, 2004, p. 77), o que leva o conhecimento a assumir um caráter parcial, sendo a identidade vista como um processo (FISCHER, 2004; MOURA, 2004). Nessa perspectiva, o trabalho com as histórias de vida atribui centralidade à linguagem "como constituinte da realidade. É entender os depoimentos obtidos via história de vida como fruto de práticas discursivas, as quais por sua vez são históricas, porque contingentes" (FISCHER, 2004, p. 11). Para Abrahão (2004) e Souza (2012), a narratividade contribui para a autocompreensão, para o conhecimento de si, quebrando o fluxo espaço-temporal linear de dar sentido às trajetórias pessoais e coletivas.

Quanto às narrativas, Lani-Bayle (2012, p. 75) destaca a importância do fluxo narrativo, de um envolvimento desejante e voluntário do sujeito, e não um caminho de obrigatoriedade, pois as narrativas obrigatórias são características das sociedades autoritárias".

As narrativas são produzidas no tempo, tempo do triplice presente (RICOEUR, 1994) vivido de forma ativa pelo sujeito de memória, que seleciona, articula e compartilha a trama
(ABRAHÃO, 2004; BRAGANÇA, 2012). Nos textos, percebemos o enfoque em um movimento essencialmente coletivo e político de construção das narrativas (CONSTANTINO, 2004; ARANGO, 2012; OLIVEIRA, 2012).

As reflexões sobre identidade estão muito presentes nos textos, uma identidade em processo e que rompe com a linearidade, incorporando múltiplas dimensões presentes na construção da subjetivação (MOURA, 2004). Processo profundamente relacionado à formação, como "duas faces da mesma moeda" (GABRIEL, 2012, p. 207), “a formação do(a) professor(a) passa pelo lugar da produção da pessoa, pelos diferentes movimentos constitutivos das identidades" (RIOS, 2012, p. 96).

Além do olhar dirigido aos conceitos fundamentais trabalhados, buscamos também apreender, na leitura dos textos, os caminhos metodológicos que têm sido construídos pela pesquisa (auto)biográfica, no campo da formação de professores. Observamos nos trabalhos do I CIPA uma ênfase em abordagens orais, por meio de entrevistas, e no V CIPA o trabalho sobre suporte escrito ou a confluência de diversos dispositivos. Adentramos, então, em cada texto, com objetivo de visualizar formas específicas de trabalho.

\section{Caminhos metodológicos da pesquisa (auto)biográfica na formação de professores}

Tanto em pesquisa anteriormente realizada (BRAGANÇA, 2008) como a que agora apresentamos, os trabalhos brasileiros têm se centrado especialmente nos caminhos que cruzam investigação e formação, ou seja, a pesquisa não tem como foco apenas a produção de conhecimento específico sobre determinado tema/problema, mas, partindo de um movimento dialético, busca a perspectiva de ao mesmo tempo produzir conhecimento e for- 
mação para todos os envolvidos no processo de investigação.

Os trabalhos aqui destacados inserem-se nessa perspectiva teórico-metodológica. 0 texto de Barreiro (2012) apresenta o desenvolvimento de oficinas de investigação-formação.

[...] a metodologia adotada tem sido bastante semelhante à descrita por Josso (2004). Os alunos marcam uma data em que deverão trazer escrita ou esquematizada sua história de vida ou de formação. Busco deixar livre o foco, pois alguns necessitam descrever fatos pessoais para chegarem a perceber suas atitudes profissionais e outros preferem manter seus relatos mais a nivel escolar, profissional, e não revelar fatos mais íntimos. Entende-se que, ainda que o aluno não revele ao grupo suas memórias mais pessoais, o trabalho de escrever 'Como venho me tornando/formando professor ao longo da vida?' certamente evoca memórias pessoais que poderão ser ressignificadas sem a mediação do grupo. (BARREIRO, 2012, p. 189-190)

Rios (2012) desenvolve o que denomina de oficinas biográficas inspiradas teoricamente nos ateliês biográficos.

[...] Foram produzidos memoriais de formação durante as Oficinas Biográficas. [...] As 'Oficinas biográficas' inspiraram-se teoricamente nos ateliês biográficos (DELORY-MOMBERGER, 2006, p. 359), os quais são tomados como 'procedimentos que inscrevem a história de vida em uma dinâmica prospectiva [...] e visa fazer emergir seu projeto pessoal, considerando a dimensão do relato como construção da experiência do sujeito e da história de vida aberto ao projeto de si'. As atividades das Oficinas trouxeram as vivências dos docentes através de uma arquitetônica dialógica bahktiniana, em que a interação foi o elemento principal na constituição do 'eu' na relação com o 'outro'. (RIOS, 2012, p. 92)

É interessante registrar que as propostas de Barreiro (2012) e Rios (2012) dialogam com as abordagens desenvolvidas, respectivamente, por Josso (2002) e por Delory-Momberger (2006), tendo denominações específicas, a sa- ber, Seminários de Histórias de Vida em Formação e ateliês biográficos; os desdobramentos metodológicos, entretanto, aproximam-se de oficinas ancoradas em diversos dispositivos de narrativa oral e escrita.

Furlaneto (2012) relata trabalho de formação continuada de professores desenvolvido no cotidiano de uma escola por meio de diversos dispositivos de mediação pedagógica.

Acreditávamos que juntos, pesquisadores e professores, poderíamos ampliar o sentido da indisciplina, mais provavelmente das indisciplinas presentes na escola. Para isso, foram disponibilizados diferentes dispositivos de mediação pedagógica: selecionamos filmes, músicas e poemas, sugerimos desenhos e colagens e organizamos vivências cuja temática girava em torno da indisciplina. Consideramos importante proporcionar aos professores experiências formativas, partindo-se do pressuposto de que elas marcam aqueles que as vivenciam. $(2012$, p. 48)

Fortuna (2012a; 2012b) apresenta o trabalho com a ludobiografia/encontros ludográficos que articulam jogo e biografia em contextos de formação continuada de professores.

Segundo Staccioli $(2005$, p. 93) 'a ludobiografia é uma modalidade de jogo que prevê o contar de si mesmo e dos outros, o mostrar-se aos outros, o acolher as histórias pessoais que outros colocam em evidência no jogo'. (FORTUNA, 2012a, p. 178)

Nesse sentido, a ludobiografia, uma vez transformada em técnica de coleta de dados sobre a formação lúdica do professor, considera com especial atenção as histórias de brincar relativas à infância dos professores, convencida de que nelas há pistas importantes para a compreensão do seu devir como professores que brincam. (FORTUNA, 2012a, p. 181)

Nas propostas de Furlaneto (2012) e Fortuna (2012a), percebemos como fio comum a multiplicidade de dispositivos/dinâmicas orais e/ou escritas, como alternativas de práticas de formação narrativa. A estimulação da recordação é outra dinâmica formativa que consiste 
na "reprodução (reapresentação), por meio de áudio e/ou vídeo, de um episódio/aula gravado com a finalidade de permitir ao espectador/ ouvinte (geralmente o docente ou o discente que o protagonizou) recordar e relatar os seus pensamentos e decisões, durante o mesmo" (SIMÃO, 2012, p. 108). Nessa perspectiva, temos o uso do vídeo como suporte e o foco na reflexão oral e partilhada entre professores e pesquisadores.

A seguir, destacamos estudos que, usando diferentes denominações, tomam a escrita autobiográfica como foco do trabalho e da formação. Vicentini (2012) apresenta o estudo de memoriais de formação de professores participantes de um curso para tutores do curso de gestão do currículo direcionado a professores coordenadores e oferecido à distância. A autora apresenta o memorial de formação como um "instrumento a partir do qual os professores poderiam refletir sobre suas experiências na escola, aprendendo ou ensinando" (2012, p. 167).

Oliveira (2012) faz um relato do trabalho que desenvolve com estudantes da graduação em pedagogia, por meio da autobiografia educativa.

[...] comecei há um bom número de anos a pedir a meus alunos que me contassem sua história de leitor e escritor: como tinha se construído, ao longo da vida e antes mesmo da entrada na escola, sua relação com a escrita. (OLIVEIRA, 2012, p. 66)

[...] Num segundo tempo, sugeri que formassem pequenos grupos e que cada participante narrasse aos demais a sua história de vida e formação para depois poderem compartilhar sua reflexão com toda a turma. (OLIVEIRA, 2012, p. 66)

[...] Para o relato final, tenho pedido que cada um, retomando o que já escreveu e refletiu, redija sua autobiografia de formação [...]. (OLIVEIRA, 2012, p. 70)

Na mesma direção, identificamos o romance de formação - bildungsroman - como dis- positivo de pesquisa-formação. Segundo Pereira (2012, p. 142) “o bildungsroman é um tipo de narrativa que se caracteriza pela formação do protagonista e do leitor nos próprios atos de escrita e leitura, respectivamente". Tendo como referência os estudos de Louis Dumont (s/d), Araújo (2012, p. 79) afirma que o bildungsroman “implica a ideia de movimento, de trajeto, de percurso de um personagem em ordem a uma maturação".

O romance de formação consiste em 'uma intensificação da experiência subjetiva, no sentido da narrativa das experiências pessoais, do cotidiano privado, representando o momento ideal da reconciliação entre indivíduo e realidade social coletiva, uma síntese realizada entre a subjetividade individual e o sentido universal da história coletiva'. (PEREIRA, 2012, p. 150)

0 'romance de formação', se pela sua relação com o tempo se aproxima, por um lado, da autobiografia; por outro lado, distingue-se dela por enfatizar aquilo que é mais geral e mais abstrato na figura do humano: é, portanto, a alma humana universal que mais interessa no melhor 'romance de formação', pois 'a imagem do homem em devir perde o seu caráter privado e desemboca na esfera espaçosa da existência histórica'. (BAKHTIN, 1992, p. 240 apud ARAÚJO, 2012, p. 92)

Percebemos, assim, os fios comuns que unem as propostas de memorial de formação, autobiografia formativa e romance de formação como escritos que revelam a trajetória de formação trilhada pelo sujeito. Por serem escritos pelos próprios sujeitos, consistem em autobiografias e todos apresentam foco no processo formativo vivido por seu autor nas itinerâncias de sua vida.

Mas, nos capítulos dos livros do I e do $\mathrm{V}$ CIPA, encontramos, também, abordagens centradas na investigação em torno do professor e de seus processos de formação. Nessas pesquisas, observamos a possibilidade de uso de diversas fontes, tais como narrativas orais, 
epístolas, fotos, vídeos, filmes, documentos (ABRAHÃO, 2004).

Barbosa (2012) desenvolve pesquisa em memoriais acadêmicos, escritos por professores, entre os anos de 1993 e 2000, e, em diálogo com Passeggi (2008b), define essa modalidade de escrito autobiográfico: o memorial acadêmico é, desse modo, representativo de um investimento de aparar a si mesmo (PASSEGGI, 2008b), considerado como possibilidade de retomada dos fossos da trajetória profissional, de reconceitualização e de novas reflexões sobre ações pretéritas (BARBOSA, 2012, p. 224).

Cunha (2012) realiza pesquisa tendo como fonte a coleção de livros e cadernos de um professor. "O estudo dos cadernos marca uma das linhas de atuação e investigação como escrituras ordinárias" (CUNHA, 2012, p. 197). Portal (2012) trabalha com cartas e outros documentos pessoais.

Cunha (2008) também faz uso das cartas como instrumento de pesquisa e a partir da análise de trechos dessas cartas, procura dar ênfase às narrativas que tratam do cotidiano escolar de professoras, onde estão descritas/representadas as situações vivenciadas no dia a dia da sala de aula, destacando os significados atribuídos a seu papel de professoras primárias. Para o autor, o uso das cartas contribui pelo seu caráter espontâneo, levando a uma leitura muito rica em detalhes, que favorecem uma análise detalhada do cotidiano dessas professoras. (PORTAL, 2012, p. 94)

$E$, finalmente, destacamos a literatura testemunhal (ARANGO, 2012, p. 214), que "consiste em uma literatura de resistência e se distingue por três aspectos principais: a proeminência do testemunho, a natureza biográfica e autobiográfica da narrativa, a vontade documentarista agenciada por um escritor-mediador e a relação ficção-realidade".

Nessas perspectivas de pesquisa, observamos sentidos fundacionais da abordagem narrativa (ARANGO, 2012, p. 216) pela valorização do "sujeito produtor de conhecimento situado fora da academia e do discurso oficial, que atravessa várias etapas: relatar, escutar, transcrever, voltar a relatar, armar o texto para dar conta da razão de ser e o estado das relações de poder, mediadas pela linguagem, na vida cotidiana de gente comum".

\section{Alguns indícios}

Esse sobrevoo sobre os capítulos do livro do I CIPA e da coleção de nove livros do V CIPA apresenta pistas sobre o caminho percorrido pela produção no campo. Por um lado, o quantitativo de trabalhos da primeira e da quinta edições do congresso por si só já aponta para o crescimento da produção da área. Por outro, a leitura que fizemos dos 45 capítulos também permitiu perceber o aprofundamento teórico-metodológico do campo. Observamos que, no universo de pesquisas e trabalhos teóricos apresentados nos capítulos estudados - tanto os que apresentam objetivos essencialmente teóricos, com foco na investigação, como os que apresentam objetivos práticos, com foco na formação, como os que apresentam objetivos emancipatórios, com foco na investigação-formação - circula como fio articulador a formação humana. Tanto no livro do CIPA I como na coleção do $\mathrm{V}$, essa temática não se circunscreveu a um eixo específico, no caso do I, nem a um livro específico, no caso do $\mathrm{V}$, mas se colocou como um conceito transversal, de modo que a seleção considerou o conjunto dos livros, e não apenas os especificamente direcionados à formação de professores.

A realização de recente estudo sobre o conjunto de trabalhos dos $C D^{3}$ permite fazer uma observação em relação à natureza desses dois suportes da produção dos CIPA: os anais em $C D$ e os livros. Enquanto, nos primeiros,

3 A ser publicado. Diferentemente dos textos que compõem os livros, os CDs contêm trabalhos apresentados em Sessões de Comunicações, de pôsteres eu de rodas de conversa. 
observamos um grande número de pesquisadores iniciantes, bem como de pesquisas em andamento, em âmbito de mestrado e doutorado, nos segundos, encontramos a prevalência de trabalhos realizados no âmbito de grupos de pesquisa já consolidados. Se, nos trabalhos apresentados nos CD, identificamos alguns que não apresentam diálogo específico com a pesquisa/formação (auto)biográfica e/ou construídos a partir de outros campos de estudo, buscando uma aproximação da abordagem (auto)biográfica, os capítulos dos livros foram construídos a partir das referências teórico-metodológicas do campo (auto) biográfico. Nesse aspecto, percebemos uma diferença entre a produção do I e do V CIPA; no I, observamos uma maior busca de apoio em referenciais das ciências da educação, como a História, a Filosofia, a Sociologia e a Psicologia, no $V$, os capítulos dos livros apoiam-se prioritariamente na literatura do campo da pesquisa (auto)biográfica, indicando um aprofundamento epistêmico da produção.

Essa questão se relaciona também ao enfoque metodológico: no I CIPA, houve um destaque para a história oral, referencial teórico-metodológico específico do campo da História, com ênfase em abordagens orais, especialmente por meio de entrevistas. No $\mathrm{V}$ CIPA, registra-se a presença mais significativa das histórias de vida e das narrativas de formação, com trabalho em suporte escrito ou por meio de dispositivos diversos. O número de participantes é variado e depende da proposta e do contexto da pesquisa, sendo muitas desenvolvidas em ambientes coletivos de formação inicial, continuada e realizadas em contexto escolar, tendência mais presente no V CIPA. Um significativo conjunto de textos não indica a metodologia de análise de dados, fato que pode indicar uma maior preocupação com a socialização do processo da pesquisa do que com os resultados.
Retomando a classificação desenvolvida por Nóvoa (1992), é interessante observar que as pesquisas apresentadas no I CIPA se centram especialmente em objetivos teóricos relacionados à investigação, com foco na profissão e na prática docente, já os do V estão centrados em objetivos emancipatórios relacionados à investigação-formação, focalizando, preferencialmente, o atravessamento das três dimensões, envolvendo a pessoa, a prática e a profissão. O que levantamos no estudo realizado consiste de indícios de um movimento de aprofundamento do campo rumo, não ao isolamento dos campos disciplinares, inclusive porque a abordagem (auto)biográfica se caracteriza pelo atravessamento inter e transdisciplinar, mas tendo em vista o fortalecimento da fundamentação epistêmica do campo e para voos instituintes quanto à pesquisa em educação.

Do ponto de vista teórico-metodológico, observamos o aprofundamento de conceitos, a diversidade e, concordando com Larrosa (2004), a criatividade e o atravessamento interdisciplinar do campo (auto)biográfico.

Pineau (2012, p. 139), reflete sobre origem do I CIPA, afirmando:

Ao promover teorias e práticas (auto)biográficas, ainda emergentes e dispersas no nível epistemo-metodológico das novas Ciências Humanas, Maria Helena dava prova de uma grande visão profética. Ela tinha vislumbrado, através da biodiversidade, às vezes desnorteadora das comunicações, a amplidão sociocognitiva histórica possivel da emergência social de um movimento de biografização vital para a formação humana. Essa emergência não se constitui sozinha. É uma aventura pessoal, social e cultural, mas também institucional, ou seja, trata-se de uma busca transdisciplinar de descobertas e transformações biocognitivas e biopolíticas, com riscos e perigos.

Na reflexão do autor, encontramos indícios potentes e a advertência sobre a importância de um exercício de avaliação dirigido à produ- 
ção do CIPA. A produção ainda emergente e dispersa, é caracterizada por uma biodiversidade de comunicações, em 2004, mas, ao longo dos anos, houve o delineamento de uma da ampliação biocognitiva possível e um movimento

\section{Referências}

ABRAHÃO, Maria Helena Menna Barreto. Um estudo da expressividade epistêmico-metodológica das pesquisas de cunho (auto)biográfico, evidenciada no Congresso Internacional de Pesquisa (Auto)Biográfica - CIPA (Edições de 2004/2006/2008/2010 e 2012). RS: Projeto de Pesquisa, CNPq, 2013.

BRAGANÇA, Inês Ferreira de Souza. Histórias de vida e formação de professores/as: um olhar dirigido à literatura educacional. In: SOUZA, Elizeu Clementino de; MIGNOT, Ana Chrystina Venancio (Orgs.). Histórias de vida e formação de professores. Rio de Janeiro: Quartet; Faperj, 2008. p. 65-88.

CERTEAU, Michel. A invenção do cotidiano: artes do fazer. Tradução de Ephraim Ferreira Alves. Petrópolis, RJ: Vozes, 2011.

DELORY-MOMBERGER, Christine. Formação e socialização: os ateliês biográficos de Projeto. Educação e Pesquisa, São Paulo, v. 32, n. 2, p. 359-371, mai./ ago. 2006.

JOSSO, Marie-Christine. Experiências de vida e formação. Tradução de José Claudino e Júlia Vieira. Natal: EDUFRN; São Paulo: Paulus, 2010.

NÓVOA, António (Org.). Vidas de professores. Portugal: Porto Editora, 1992.

PINEAU, Gaston. A tríplice aventura (auto)biográfica: a expressão, a socialização e a formação. In: ABRAHÃO, Maria Helena Menna Barreto; PASSEGGI, Maria da Conceição. (Orgs.). Dimensões epistemológicas e metodológicas da pesquisa (auto)biográfica). Natal: EDUFRN; Porto Alegre: EDIPUCRS; Salvador: EDUNEB, 2012. p. 139-158.

PINEAU, Gaston. As histórias de vida em formação: gênese de uma corrente de pesquisa-ação-formação existencial. Educação e Pesquisa, São Paulo, v. 32, n. 2, p. 329-343, mai./ago. 2006. de biografização vital para a formação humana além do destaque para os riscos e perigos. Penetrar nessas tensões da produção do campo constituiu o movimento/desafio da pesquisa realizada e apresentada neste texto.

RICOEUR, P. Tempo e narrativa. Tradução de Constança Marcondes Cesar. Campinas, SP: Papirus, 1994. (t. 1).

\section{Referências dos capítulos do livro do I CIPA e da coleção do V CIPA, que constituíram fonte da pesquisa apresentada:}

ABRAHÃO, Maria Helena Menna Barreto (Org.). A aventura (auto)biográfica: teoria e empiria. Porto Alegre: EDIPUCRS, 2004.

ABRAHÃO, Maria Helena Menna Barreto. Pesquisa (auto)biográfica: tempo, memória e narrativas. In: ABRAHÃO, Maria Helena Menna Barreto (Org.). A aventura (auto)biográfica: teoria e empiria. Porto Alegre: EDIPUCRS, 2004. p. 201-224.

ALCOFORADO, Luís. As histórias de vida na educação e formação de adultos: o desafio de promover uma auto(eco)confrontação transformativa e emancipatória. In: CUNHA, Jorge Luiz da; VICENTINI, Paula Perin (Orgs.). Corpos, saúde, cuidados de si e aprendizagens ao longo da vida: desafios (auto)biográficos. Porto Alegre: EDIPUCRS; Salvador: EDUNEB; Natal: EDUFRN: 2012. p. 29-54. (Coleção Pesquisa (Auto) biográfica: temas transversais)

ALHEIT, Peter. Conhecimento biográfico e "aprendizagem transitória". In: CUNHA, Jorge Luiz da; VICENTINI, Paula Perin (Orgs.). Corpos, saúde, cuidados de si e aprendizagens ao longo da vida: desafios (auto) biográficos. Porto Alegre: EDIPUCRS; Salvador: EDUNEB, Natal: EDUFRN, 2012. p. 53-73. (Coleção Pesquisa (Auto)biográfica: temas transversais)

ARANGO, Gabriel Jaime Murillo. Memoria y testimonio em tiempos de oscuridad. In: PASSEGGI, Maria da Conceição; ABRAHÃO, Maria Helena Menna Barreto (Orgs.). Dimensões epistemológicas e metodológi- 
cas da pesquisa (auto)biográfica). Natal: EDUFRN; Porto Alegre: EDIPUCRS; Salvador: EDUNEB, 2012. p. 205-234. (Coleção Pesquisa (Auto)biográfica: temas transversais)

ARAÚJO, Alberto Filipe; RIBEIRO, José Augusto Lopes. $O$ romance de formação e a experiência de vida. In: CUNHA, Jorge Luiz da; VICENTINI, Paula Perin (Orgs.).

Corpos, saúde, cuidados de si e aprendizagens ao longo da vida: desafios (auto)biográficos. Porto Alegre: EDIPUCRS; Salvador: EDUNEB, Natal: EDUFRN, 2012. p. 77-103. (Coleção Pesquisa (Auto)biográfica: temas transversais)

ARFUCH, Leonor. Devenires auto/biográficos: los objetos, el tempo, el lugar. In: PASSEGGI, Maria da Conceição; ABRAHÃO, Maria Helena Menna Barreto (Orgs.). Dimensões epistemológicas e metodológicas da pesquisa (auto)biográfica). Natal: EDUFRN; Porto Alegre: EDIPUCRS; Salvador: EDUNEB, 2012. p. 235-278. (Coleção Pesquisa (Auto)biográfica: temas transversais)

BARBOSA, Tatyana Mabel Nobre. O memorial acadêmico como l'âge mûr. In: EGGERT, Edla; FISCHER, Beatriz Dautd (Orgs.). Gênero, geração, infância, juventude e família. Porto Alegre: EDIPUCRS; Salvador: EDUNEB, Natal: EDUFRN, 2012. p. 219-234. (Coleção Pesquisa (Auto)biográfica: temas transversais)

BARREIRO, Cristhianny Bento. Oficinas de investigação-formação e potencialidade na formação de professor contemporâneo. In: ABRAHÃO, Maria Helena Menna Barreto (Org.). Pesquisa (auto)biográfica em rede. Porto Alegre: EDIPUCRS; Salvador: EDUNEB, Natal: EDUFRN, 2012. p. 185- 197. (Coleção Pesquisa (Auto)biográfica: temas transversais)

BASTOS, Maria Helena Camara. A liturgia do tempo: Marc-Antoine Jullien e a arte de governar-se e educar-se. In: PASSEGGI, Maria da Conceição; ABRAHÃO, Maria Helena Menna Barreto (Orgs.). Dimensões epistemológicas e metodológicas da pesquisa (auto)biográfica). Natal: EDUFRN; Porto Alegre: EDIPUCRS; Salvador: EDUNEB, 2012. p. 245-278. (Coleção Pesquisa (Auto)biográfica: temas transversais)

BOLÍVAR, Antonio. Metodología de la investigación biográfico-narrativa: recogida y análises de datos. In: PASSEGGI, Maria da Conceição; ABRAHÃO, Maria
Helena Menna Barreto (Orgs.). Dimensões epistemológicas e metodológicas da pesquisa (auto) biográfica). Natal: EDUFRN; Porto Alegre: EDIPUCRS; Salvador: EDUNEB, 2012. p. 79-109. (Coleção Pesquisa (Auto)biográfica: temas transversais)

BRAGANÇA, Inês Ferreira de Souza. Trajetórias de vida e formação de professoras: suas biografias educativas. In: SOUZA, Elizeu Clementino de.; BRAGANÇA, Inês Ferreira de Souza (Orgs.). Memória, dimensões sócio-históricas e trajetórias de vida. Porto Alegre: EDIPUCRS, 2012. p. 193-219. (Coleção Pesquisa (Auto)biográfica: temas transversais)

CATANI, Denice Barbara; VICENTINI, Paula Perin. Lugares sociais e inserção profissional: o magistério como modo de vida nas autobiografias de professores. In: ABRAHÃO, Maria Helena Menna Barreto (Org.). A aventura (auto)biográfica: teoria e empiria. Porto Alegre: EDIPUCRS, 2004. p. 267-291.

CONSTANTINO, Núncia Santoro. Teoria da história e reabilitação da oralidade: convergência de um processo. In: ABRAHÃO, Maria Helena Menna Barreto (Org.). A aventura (auto)biográfica: teoria e empiria. Porto Alegre: EDIPUCRS, 2004, p. 37-74.

CUNHA, Maria Teresa Santos. Na insegurança das palavras: livros e cadernos pessoais na biografia de um professor. In: DIAS, Cleuza Maria Sobral; PERES, Lúcia Maria Vaz (Orgs.). Territorialidades: imaginário, cultura e invenção de si. Porto Alegre: EDIPUCRS; Salvador: EDUNEB, Natal: EDUFRN, 2012. p. 187-209. (Coleção Pesquisa (Auto)biográfica: temas transversais)

DELORY-MOMBERGER, Christine. Prefácio. In: PASSEGGI, Maria da Conceição; ABRAHÃO, Maria Helena Menna Barreto (Orgs.). Dimensões epistemológicas e metodológicas da pesquisa (auto)biográfica). $\mathrm{Na}$ tal: EDUFRN; Porto Alegre: EDIPUCRS; Salvador: EDUNEB, 2012, p. 9-15. (Coleção Pesquisa (Auto)biográfica: temas transversais)

EGGERT, Edla. Quem pesquise se pesquisa? Uma provocação a fim de criar um espaço especulativo ao ato investigativo. In: ABRAHÃO, Maria Helena Menna Barreto (Org.). A aventura (auto)biográfica: teoria e empiria. Porto Alegre: EDIPUCRS, 2004. p. 549-584. 
FISCHER, Beatriz T. Daudt. Foucault e as histórias de vida: aproximações e que tais... In: ABRAHÃO, Maria Helena Menna Barreto (Org.). A aventura (auto) biográfica: teoria e empiria. Porto Alegre: EDIPUCRS, 2004. p. 143-161.

FONTOURA, Helena Amaral; PIERRO, Gianine Maria de Souza; FERNANDES, Glaucia Braga Ladeira; SILVA, Marcia Maria; RIBAS, Maria Cristina Cardoso; NHARY, Tania Maria Costa; GASPARELLO, Vânia Medeiros. A arte como imagem que evoca a memória de formação - história em um grupo de pesquisa. In: DIAS, Cleuza Maria Sobral; PERES, Lúcia Maria Vaz (Orgs.). Territorialidades: imaginário, cultura e invenção de si. Porto Alegre: EDIPUCRS; Salvador: EDUNEB, Natal: EDUFRN: 2012. p. 45-67. (Coleção Pesquisa (Auto)biográfica: temas transversais)

FORTUNA, Tânia Ramos. Ludobiografia: uma invenção metodológica em pesquisa (auto)biográfica em educação. In: PASSEGGI, Maria da Conceição; ABRAHÃO, Maria Helena Menna Barreto (Orgs.). Dimensões epistemológicas e metodológicas da pesquisa (auto)biográfica). Natal: EDUFRN; Porto Alegre: EDIPUCRS; Salvador: EDUNEB, 2012a. p. 165-202. (Coleção Pesquisa (Auto)biográfica: temas transversais)

FORTUNA, Tânia Ramos. Professores que brincam: contribuições da ludobiografia para a compreensão da formação lúdica do professor. In: ABRAHÃO, Maria Helena Menna Barreto; FRISON, Lourdes Maria Bragagnolo (Ogrs.). Práticas docentes e práticas de (auto)formação. Porto Alegre: EDIPUCRS; Salvador: EDUNEB, Natal: EDUFRN, 2012. p. 133-146b. (Coleção Pesquisa (Auto)biográfica: temas transversais)

FURLANETTO, Ecleide Cunico. A contribuição de alunos para a formação docente. In: EGGERT, Edla; FISCHER, Beatriz Dautd (Orgs.). Gênero, geração, infância, juventude e família. Porto Alegre: EDIPUCRS; Salvador: EDUNEB, Natal: EDUFRN, 2012. p. 47-56. (Coleção Pesquisa (Auto)biográfica: temas transversais)

GABRIEL, Gilvete de Lima. Formação inicial e continuada. Narrativas autobiográficas e os processos de aprendizagem da profissão docente ao longo da vida. In: CUNHA, Jorge Luiz da; VICENTINI, Paula Perin (Orgs.). Corpos, saúde, cuidados de si e aprendi- zagens ao longo da vida: desafios (auto)biográficos. Porto Alegre: EDIPUCRS; Salvador: EDUNEB; Natal: EDUFRN, 2012. p. 193-227. (Coleção Pesquisa (Auto) biográfica: temas transversais)

GOODSON, Ivor F. Developing life and work histories of teachers. In: ABRAHÃO, Maria Helena Menna Barreto (Org.). A aventura (auto)biográfica: teoria e empiria. Porto Alegre: EDIPUCRS, 2004. p. 245-266.

JOSSO, Marie-Christine. Fecundação mútua de metodologias e de saberes em pesquisa-formação experiencial: observações fenomenológicas de figuras do acompanhamento e novas conceituações. In: PASSEGGI, Maria da Conceição; ABRAHÃO, Maria Helena Menna Barreto (Orgs.). Dimensões epistemológicas e metodológicas da pesquisa (auto) biográfica). Natal: EDUFRN; Porto Alegre: EDIPUCRS; Salvador: EDUNEB, 2012. p. 113-143. (Coleção Pesquisa (Auto)biográfica: temas transversais)

LANI-BAYLE, Martine. Narrativas de vida: motivos, limites e perspectivas. In: PASSEGGI, Maria da Conceição; ABRAHÃO, Maria Helena Menna Barreto (Orgs.). Dimensões epistemológicas e metodológicas da pesquisa (auto)biográfica). Natal: EDUFRN; Porto Alegre: EDIPUCRS; Salvador: EDUNEB, 2012. p. 59-78. (Coleção Pesquisa (Auto)biográfica: temas transversais)

LARROSA, Jorge. Notas sobre narrativa e identidad. In: ABRAHÃO, Maria Helena Menna Barreto (Org.). A aventura (auto)biográfica: teoria e empiria. Porto Alegre: EDIPUCRS, 2004. p. 11-22.

MONTEIRO, Filomena Arruda; EVANGELISTA, Edson Gomes; MARIANI, Fábio; CARDOSO, Lilian A. Maciel. Formação docente, processos de desenvolvimento e de aprendizagens: conhecimento e práticas ressignificados pelas narrativas de formação/investigação. In: ABRAHÃO, Maria Helena Menna Barreto; FRISON, Lourdes Maria Bragagnolo (Orgs.). Práticas docentes e práticas de (auto)formação. Porto Alegre: EDIPUCRS; Salvador: EDUNEB; Natal: EDUFRN, 2012, p 165-181. (Coleção Pesquisa (Auto)biográfica: temas transversais)

MOSQUERA, Juan José Mourino; STOBÄUS, Claus. Narrativas de vida: fundamentos de uma dimensão 
metodológica. In: ABRAHÃO, Maria Helena Menna Barreto (Org.). A aventura (auto)biográfica: teoria e empiria. Porto Alegre: EDIPUCRS, 2004. p. 75-91.

MOURA, Eliana Perez Gonçalves. Da pesquisa (auto) biográfica à cartografia: desafios epistemológicos no campo da Psicologia. In: ABRAHÃO, Maria Helena Menna Barreto (Org.). A aventura (auto)biográfica: teoria e empiria. Porto Alegre: EDIPUCRS, 2004. p. 119-142.

OLIVEIRA, Anne-Marie Milon. Escrever, inscrever-se, autorizar-se, autobiografias e formação existencial. In: ABRAHÃO, Maria Helena Menna Barreto; FRISON, Lourdes Maria Bragagnolo (Orgs.). Práticas docentes e práticas de (auto)formação. Porto Alegre: EDIPUCRS; Salvador: EDUNEB; Natal: EDUFRN, 2012. p. 43-78. (Coleção Pesquisa (Auto)biográfica: temas transversais)

OLIVEIRA, Valesca Fortes; OLIVEIRA, Vânia Fortes; FABRÍCIO, Laura Elise de Oliveira. O oral e a fotografia na pesquisa qualitativa. In: ABRAHÃO, Maria Helena Menna Barreto (Org.). A aventura (auto)biográfica: teoria e empiria. Porto Alegre: EDIPUCRS, 2004. p. 163-180.

PASSEGGI, Maria da Conceição; ABRAHÃO, Maria Helena Menna Barreto. Apresentação. In: PASSEGGI, Maria da Conceição; ABRAHÃO, Maria Helena Menna Barreto (Orgs.). Dimensões epistemológicas e metodológicas da pesquisa (auto)biográfica). Natal: EDUFRN; Porto Alegre: EDIPUCRS; Salvador: EDUNEB, 2012. p. 19-26a. (Coleção Pesquisa (Auto)biográfica: temas transversais)

PASSEGGI, Maria da Conceição; ABRAHÃO, Maria Helena Menna Barreto; DELORY-MOMBERGER, Christine. Reabrir o passado, inventar o devir: inenarrável condição de ser. In: PASSEGGI, Maria da Conceição; ABRAHÃO, Maria Helena Menna Barreto (Orgs.). Dimensões epistemológicas e metodológicas da pesquisa (auto)biográfica). Natal: EDUFRN; Porto Alegre: EDIPUCRS; Salvador: EDUNEB, 2012. p. 29-57b. (Coleção Pesquisa (Auto)biográfica: temas transversais)

PEREIRA, Marcos Villela. (Auto)formação e o potencial das novelas de formação. In: PASSEGGI, Maria da
Conceição; ABRAHÃO, Maria Helena Menna Barreto (Orgs.). Dimensões epistemológicas e metodológicas da pesquisa (auto)biográfica). Natal: EDUFRN; Porto Alegre: EDIPUCRS; Salvador: EDUNEB, 2012. p. 147-163. (Coleção Pesquisa (Auto)biográfica: temas transversais)

PERES, Lucia Maria Vaz. Apontamentos sobre polarizações mítico-simbólicas: matriciando a escrita autobiográfica de estudantes de pós-graduação. In: DIAS, Cleuza Maria Sobral; PERES, Lúcia Maria Vaz (Orgs.). Territorialidades: imaginário, cultura e invenção de si. Porto Alegre: EDIPUCRS; Salvador: EDUNEB; Natal: EDUFRN, 2012. p. 269-299. (Coleção Pesquisa (Auto)biográfica: temas transversais)

PÉREZ, Oresta López. ?Es posible que las vidas hablen?: Historias de vida de maestros y maestras téneks y nahuas de San Luis Potosí, México. In: ANTUNES, Helenise Sangoi; OLIVEIRA, Valeska Fortes de (Orgs.). Diversidade: culturas, ruralidades, migração, formação e integração. Porto Alegre: EDIPUCRS; Salvador: EDUNEB, Natal: EDUFRN, 2012. p. 115-138. (Coleção Pesquisa (Auto)biográfica: temas transversais)

PIERRÔ, Gianine Maria de Souza; FONTOURA, Helena Amaral; RIBAS, Maria Cristina Cardoso. Imagens, corpos, cantos: arte que nos(trans)formam. In: ABRAHÃO, Maria Helena Menna Barreto; FRISON, Lourdes Maria Bragagnolo (Orgs.). Práticas docentes e práticas de (auto)formação. Porto Alegre: EDIPUCRS; Salvador: EDUNEB; Natal: EDUFRN, 2012. p. 147-164. (Coleção Pesquisa (Auto)biográfica: temas transversais)

PORTAL, Leda Lísia Franciosi. Cartas: um universo desvelador de significados na formação do formador? In: ABRAHÃO, Maria Helena Menna Barreto; FRISON, Lourdes Maria Bragagnolo. (Orgs.). Práticas docentes e práticas de (auto)formação. Porto Alegre: EDIPUCRS; Salvador: EDUNEB; Natal: EDUFRN, 2012. p. 79-105. (Coleção Pesquisa (Auto)biográfica: temas transversais)

RIOS, Jane Adriana Vasconcelos Pacheco. Identidades docentes na roça: narrativas de formação. In: ANTUNES, Helenise Sangoi; OLIVEIRA, Valeska Fortes de. (Orgs.). Diversidade: culturas, ruralidades, 
migração, formação e integração. Porto Alegre: EDIPUCRS; Salvador: EDUNEB, Natal: EDUFRN, 2012. p. 89-113. (Coleção Pesquisa (Auto)biográfica: temas transversais)

SCHMUTZ-BRUN, Catherine. As múltiplas invenções da abordagem (auto)biográfica na formação inicial dos professores do secundário I e II. In: ABRAHÃO, Maria Helena Menna Barreto; FRISON, Lourdes Maria Bragagnolo (Orgs.). Práticas docentes e práticas de (auto)formação. Porto Alegre: EDIPUCRS; Salvador: EDUNEB; Natal: EDUFRN, 2012. p. 15-42. (Coleção Pesquisa (Auto)biográfica: temas transversais)

SIMÃO, Ana Maria Veiga. O valor da estimulação da recordação no desenvolvimento de práticas docentes reflexivas. In: ABRAHÃO, Maria Helena Menna Barreto; FRISON, Lourdes Maria Bragagnolo. (Orgs.). Práticas docentes e práticas de (auto)formação. Porto Alegre: EDIPUCRS; Salvador: EDUNEB; Natal: EDUFRN, 2012. p. 107-132. (Coleção Pesquisa (Auto) biográfica: temas transversais)

SOUZA, Elizeu Clementino de. O conhecimento de si, as narrativas de formação e o estágio: reflexões teórico-metodológicas sobre uma abordagem experiencial de formação inicial. In: ABRAHÃO, Maria
Helena Menna Barreto (Org.). A aventura (auto)biográfica: teoria e empiria. Porto Alegre: EDIPUCRS, 2004. p. 237-417.

SOUZA, Elizeu Clementino de. Pontes e muros: pesquisa narrativa e trajetórias (auto)biográficas - o lugar da memória e a memória do lugar na educação rural. In: SOUZA, Elizeu Clementino de.; BRAGANÇA, Inês Ferreira de Souza (Orgs.). Memória, dimensões sócio-históricas e trajetórias de vida. Porto Alegre: EDIPUCRS, 2012. p. 33-56. (Coleção Pesquisa (Auto) biográfica: temas transversais)

VICENTINI, Paula Perin; GALLEGO, Rita de Cássia; SILVA, Vivian Batista; SILVA, Milena Colazingari. Tornar-se próximo no espaço virtual: a experiência de produção do relato autobiográfico sobre os "tempos de escola" no curso de gestão de currículo para professores coordenadores. In: DIAS, Cleuza Maria Sobral; PERES, Lúcia Maria Vaz (Orgs.). Territorialidades: imaginário, cultura e invenção de si. Porto Alegre: EDIPUCRS; Salvador: EDUNEB; Natal: EDUFRN, 2012. p. 161-185. (Coleção Pesquisa (Auto)biográfica: temas transversais)

Recebido em: 04.01.2016 Aprovado em: 05.02.2016

Inês Ferreira de Souza Bragança é Pós-Doutora pelo programa de Pós-Graduação em educação da Pontifícia Universidade Católica do Rio Grande do Sul (PUC/RS) e Doutorado em Ciências da Educação pela Universidade de Évora-Portugal. Professora Adjunta da Faculdade de Formação de Professores da UERJ e Coordenadora do Mestrado em Educação Processos Formativos e Desigualdades Sociais. Procientista e Jovem cientista do nosso Estado (FAPERJ). Faz parte da Diretoria Regional da Associação Brasileira de Pesquisa (Auto)Biográfica (gestão 2014-2016), é Pesquisadora do Núcleo de Pesquisa e Extensão Vozes da Educação (UERJ). e-mail: inesbraganca@uol.com.br.

Trav. São Feliciano, 53, bloco 8/201. Fonseca-Niterói RJ Brasil-Cep: 24.120-270.

Maria Helena Menna Barreto Abrahão é Licenciada em Letras Anglo-Germânicas (UFSM); Mestre em Educação: Planejamento Educacional (UFRGS); Doutora em Ciências Humanas: Educação (UFRGS). Pesquisadora 1A CNPq. Docente Permanente na FACED/PPGEdu, na Universidade Federal de Pelotas - UFPel, onde integra a Linha de Pesquisa Cultura Escrita, Linguagens e Aprendizagens. Integra o PEAAR, Programa de Pesquisa do Centro de Investigação em Aprendizagem Autorregulada (Universidade de Lisboa).e-mail: abrahaomhmb@gmail.com.

Rua Barão de Ubá, 401, apto. 301. Bela Vista - Porto Alegre - Rio Grande do Sul - CEP: 90450-090 